\title{
Colored Clays in a Groundwater Stream, Correlating Fiber-optic Reflectance with Electrical Impedance
}

\section{Swatland $\mathbf{H J}^{*}$}

University of Guelph, Guelph, Ontario N1H 2Y8, Canada

\begin{abstract}
A bifurcated fiber-optic light guide was used to measure the colors of clays in a groundwater stream over the Upper Ordovician Queenston Formation of the Niagara Escarpment (Ontario, Canada). One branch of the light guide illuminated the samples, and the other branch gathered reflected light for spectrophotometry. Measuring Munsell rock color chips, and using the weighted-ordinate method to calculate chromaticity coordinates from reflectance spectra, the dominant chemically reduced clay was greenish-gray (Munsell $5 \mathrm{G} 6 / 1, x=0.348, y=0.352, Y \%=62.3$ ) while the dominant oxidized clay was grayish-red (Munsell 5R 4/2, $x=0.388, y=0.338, Y \%=23.8$ ). The electrical impedance of clays was correlated with $x(r=-0.92$ for capacitance and $r=0.96$ for resistance, $P<0.001$ at $10 \mathrm{kHz}$ ). The peak wavelengths for correlations were around 500 to $540 \mathrm{~nm}$. The matrix between the corallites of a Devonian fossil coral above the collection site (Eridophyllum seriale) was within the statistical range of oxidized grayish-red Ordovician shale. There was no evidence that low pH in the groundwater stream had caused the variation in clay color, thus, leaving conditions when the source shale was deposited as the most likely cause of color variation.
\end{abstract}

Keywords: Groundwater; Clay color; Fiber-optic reflectance; Electrical impedance

\section{Introduction}

Clay is a well-known aquitard whose distribution often determines the geographical location of groundwater springs, which may then cascade over the clays to produce bright colors. Clay color is important in geological stratigraphy and depositional analysis [1], and the Queenston Formation shales exposed on the Niagara Escarpment in Ontario, Canada, produce clays of different hues [2-5], variously reported as brown, red, green, gray, or blue. While the mineral basis of clay color can be contentious [6], it has been suggested that the acidity of groundwater may cause color variations in clay [7]. Subjective descriptions of clay colors are often confusing, and there is much to be gained by using objective colorimetry [8-10], or Munsell rock color standards for subjective evaluation [11].

With geological samples, it is very difficult to follow the strict protocols of CIE (Commission International de l'Éclairage) colorimetry with regard to illuminator emission spectrum, sample size and viewing angle [12]. But using a Y-shaped or bifurcated fiber-optic light guide, it is possible to illuminate small areas and collect reflected light for spectrophotometry [13]. Spectral data may be processed using the weighted-ordinate method on which the CIE system is founded; at regular intervals across the spectrum, the data are weighted by their appearance to the human eye, to give two chromaticity coordinates ( $\mathrm{x}$ and $y$ ) and a measure of luminosity (Y\%). Thus, by measuring both clays and their matching rock color standards, it is possible to minimize subjectivity. But do the color data have any real meaning?

The idea of this research was to look for relationships between fiber optic reflectance data and an independent physical property of clay - electrical impedance. Electrical resistance to a direct current is measured in ohms. But if we attempt to measure the resistance of a complex system like clay using a direct current and metal electrodes, then electrochemical reactions occur on the electrode surfaces to create miniature batteries, so now the sample is between two slowly changing resistances. This can be avoided by using an alternating current whose frequent changes of current direction cancel electrochemical changes, but now any insulating components in the system act as storage capacitors, and their alternate charging and discharging further impedes the current. Thus, electrical impedance with an alternating current is a triangular function of what, for the sake of simplicity in this report, will be termed resistance (ohms) and capacitance (farads). Resistance in clays depends on alternating current frequency and is an indication of cation-exchange capability [14].

\section{Materials and Methods}

\section{Fiber optics}

The common trunk of the fiber-optic light guide had a single illuminating fiber surrounded by six fibers to gather reflected light. The illuminator was a $100 \mathrm{~W}$ halogen source powered from a stabilized transformer. Reflected light passed through a grating monochromator and onto a side-window photomultiplier. Complete details of the apparatus are reported elsewhere [15]. The system was standardized against a white opal glass plate from a Zeiss Elrepho colorimeter, adjusting the distance between the probe tip and the plate to give maximum reflectance (sterance) at $550 \mathrm{~nm}$. Color coordinates were calculated using the 1931 weighted ordinates [12]. Spectra were tested using $t$-tests and simple correlation coefficients at each wavelength.

\section{Electrical impedance}

For electrical measurements, clay samples were impaled with parallel needles (gauge 18, axial separation $17 \mathrm{~mm}$ ) and measured with a Hewlett Packard 4262A LCR meter (Palo Alto, California) using a

*Corresponding author: Swatland HJ, University of Guelph, 33 Robinson Avenue, Guelph, Ontario N1H 2Y8, Canada, Tel: 1-519-821-7513; E-mail: swatland@ uoguelph.ca

Received September 01, 2017; Accepted September 13, 2017; Published September 19, 2017

Citation: Swatland HJ (2017) Colored Clays in a Groundwater Stream, Correlating Fiber-optic Reflectance with Electrical Impedance. Hydrol Current Res 8: 283. doi: 10.4172/2157-7587.1000283

Copyright: (c) 2017 Swatland HJ. This is an open-access article distributed under the terms of the Creative Commons Attribution License, which permits unrestricted use, distribution, and reproduction in any medium, provided the original author and source are credited. 
parallel circuit mode at $120 \mathrm{~Hz}, 1 \mathrm{kHz}$ and $10 \mathrm{kHz}$. Depth of penetration was standardized to $4 \mathrm{~cm}$ by insulating sleeves on the electrodes.

\section{Clay samples}

Wet clay samples were collected from a groundwater stream on the Niagara Escarpment north of Niagara Falls, where the Mad River runs through a preglacial notch in the escarpment, then joins the Nottawasaga River to empty eastwards into the Georgian Bay of Lake Huron (Figure 1). The full stratigraphic column of the escarpment (Cambrian, Ordovician, Silurian and Devonian) has been eroded here, so that the top layer in situ in the headwaters of the Mad River Valley is the Amabel formation of the Lower Silurian, although Devonian rocks and fossils are scattered above the top layer. As the Mad River cuts eastwards down the escarpment, the lower levels of the Clinton and Cataract Groups (Middle and Lower Silurian, respectively) are exposed above the colored shales of the Queenston Formation (Upper Ordovician). Weathering of the colored shales gives rise to colored clays. The clay samples were wrapped to maintain their original stiff, damp texture and were measured at approximately $18^{\circ} \mathrm{C}$.

\section{Hydrology}

Water temperature and $\mathrm{pH}$ were measured with a water-proof meter calibrated before each set of measurements (PC300, Oakton Instruments, Vernon Hills, IL) for a period of two years. The $\mathrm{pH}$ electrode was cleaned regularly with pepsin and $\mathrm{HCl}$ (Oakton 653-06) and stored in an appropriate medium (Oakton 653-04). During cold weather, the meter was kept warm. Measurements were made 20 secs after the ready indicator appeared.

\section{Results}

\section{Fiber-optic reflectance}

Reduced clay samples were greenish-gray (Munsell 5G 6/1, $\mathrm{x}=0.348, \mathrm{y}=0.352, \quad \mathrm{Y} \%=62.3)$ while oxidized clay samples were grayish-red (Munsell 5R 4/2, $\mathrm{x}=0.388, \mathrm{y}=0.338, \mathrm{Y} \%=23.8$ ), with color coordinates calculated from fiber-optic measurements of Munsell Rock Colors (Figure 2). Fiber-optic measurements of actual clay samples produced spectra similar in shape to the Munsell Rock Colors of Figure 2. Reduced (Figure 3) and oxidized clays (Figure 4) both showed considerable differences in luminosity.

\section{Electrical impedance}

From $120 \mathrm{~Hz}$ to $10 \mathrm{kHz}$, reduced clay had higher electrical capacitance and lower resistance than oxidized clay (Table 1). Correlations of color coordinates and electrical parameters were strongest in the $x$-axis (blue-green to orange-red), as shown in Table 2. However, significant correlations of electrical parameters with $\mathrm{Y} \%$ were also detected (Table 2). This gets complicated because, not only was the green to red hue indicative of the basic physical properties of the clay, but there was also some connection with luminosity. This may have been because oxidized clay was darker than reduced clay, as shown in Figure 2 for Munsell Rock Colors, and by noting the y-axis data in Figures 3 and 4. In summary - where was the information, in the shape of the spectrum, in the luminosity, or both?

\section{Correlations}

To work on this problem, the correlations of reflectance with electrical parameters were plotted across the spectrum. Capacitance was positively correlated with reflectance (Figure 5C) while resistance was negatively correlated with reflectance (Figure 5R). The strong

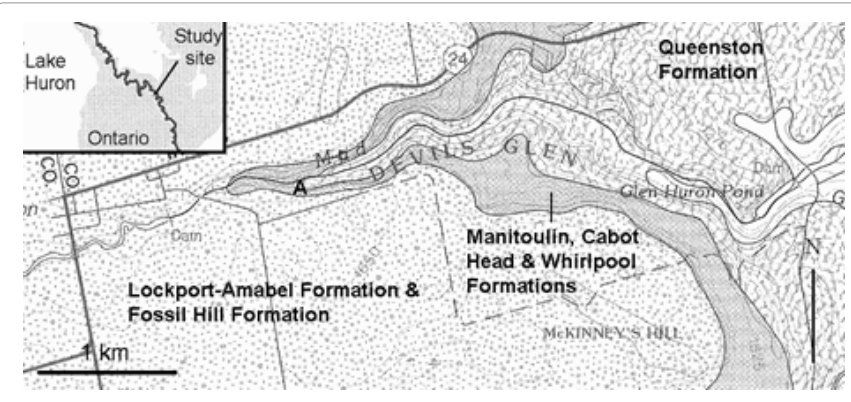

Figure 1: Location of the groundwater stream (site A), adapted from Tovell's map F-2 [3].

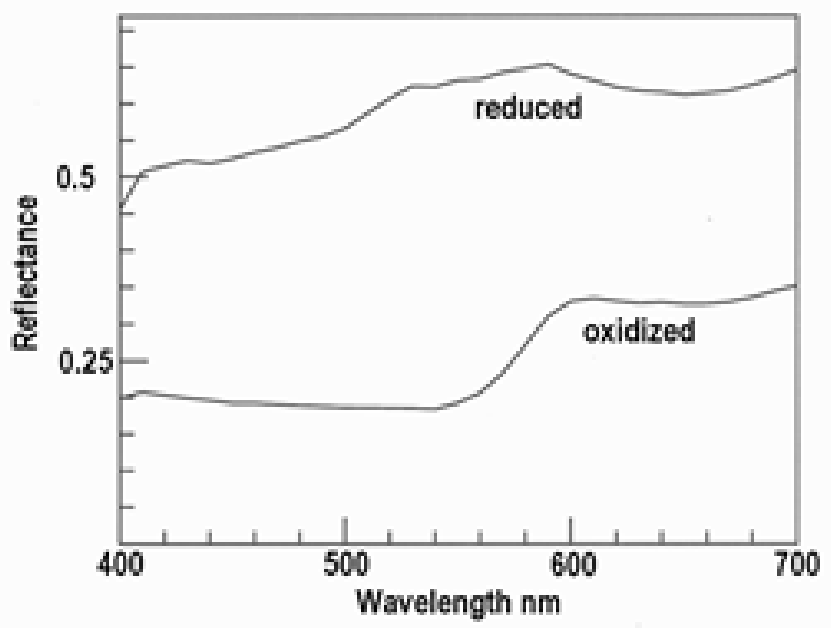

Figure 2: Fiber-optic reflectance spectra measured from the Munsell rock color chips for reduced clay (greenish-gray, Munsell 5G 6/1) and oxidized clay (grayish-red, Munsell 5R 4/2).

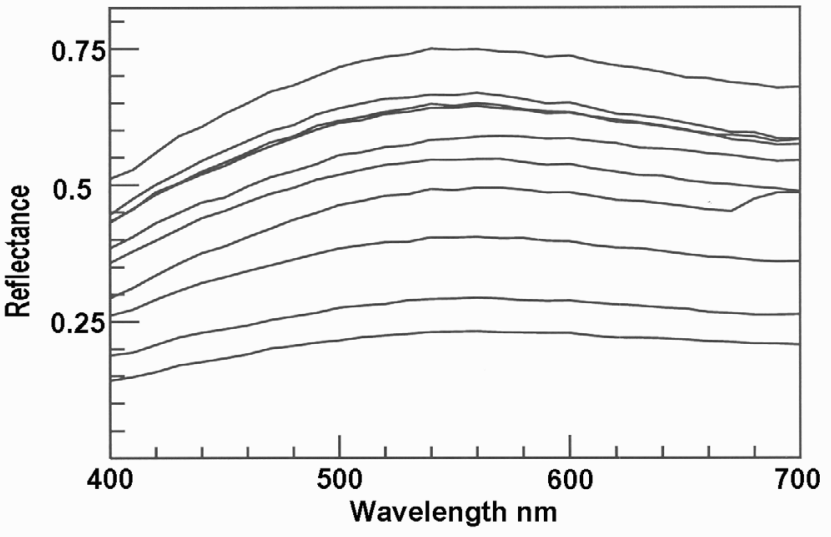

Figure 3: Fiber-optic reflectance spectra of reduced clay.

negative correlations of $x$ with capacitance (Table 2, column 2) had only a small effect from the frequency of the test current $(120$ to $10 \mathrm{kHz})$ and were strongest from 500 to $540 \mathrm{~nm}(P<0.005)$. The strong positive correlations of $x$ with resistance (Table 2, column 2) also showed little effect from the frequency of the test current, and correlations were strong from 500 to $540 \mathrm{~nm}(\mathrm{P}<0.005)$. Thus, reflectance from blue $(500 \mathrm{~nm})$ to green $(540 \mathrm{~nm})$ was the dominant sources of the strong correlations of $x$ with electrical parameters seen in Table 2, column 2. 
Citation: Swatland HJ (2017) Colored Clays in a Groundwater Stream, Correlating Fiber-optic Reflectance with Electrical Impedance. Hydrol Current Res 8: 283. doi: 10.4172/2157-7587.1000283

Page 3 of 4

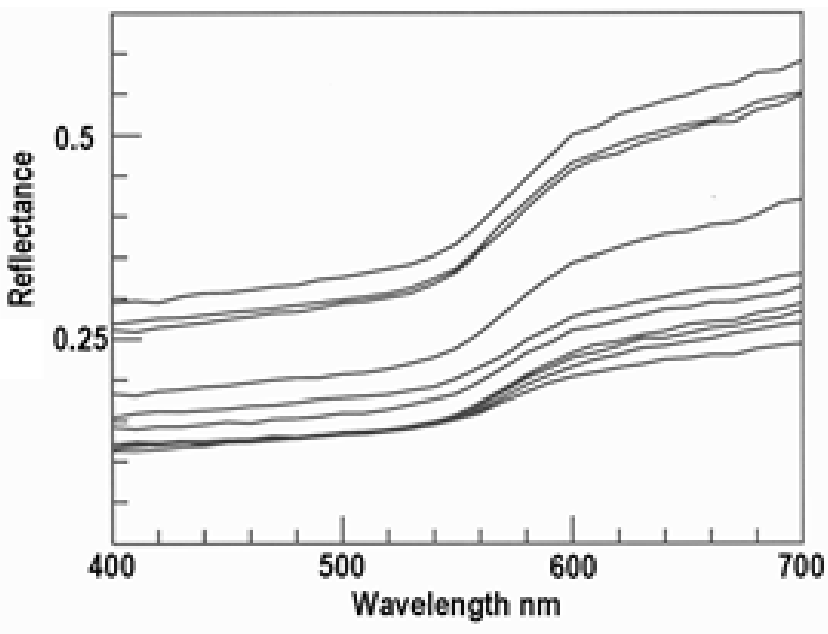

Figure 4: Fiber-optic reflectance spectra of oxidized clay.

\begin{tabular}{|c|c|c|}
\hline & Reduced & Oxidized \\
\hline $120 \mathrm{~Hz} C$ & $6.24 \mathrm{E}-7 \pm 9.35 \mathrm{E}-8$ & $2.99 \mathrm{E}-7 \pm 8.91 \mathrm{E}-9$ \\
\hline $120 \mathrm{~Hz} \mathrm{R}$ & $447.2 \pm 22.6$ & $631.3 \pm 23.7$ \\
\hline $1 \mathrm{kHz} \mathrm{C}$ & $2.18 \mathrm{E}-8 \pm 2.40 \mathrm{E}-9$ & $1.00 \mathrm{E}-8 \pm 4.24 \mathrm{E}-10$ \\
\hline $1 \mathrm{kHz} \mathrm{R}$ & $400.6 \pm 20.5$ & $591.6 \pm 21.3$ \\
\hline $10 \mathrm{kHz} C$ & $1.02 \mathrm{E}-9 \pm 1.23 \mathrm{E}-10$ & $5.88 \mathrm{E}-10 \pm 2.52 \mathrm{E}-11$ \\
\hline $10 \mathrm{kHz} \mathrm{R}$ & $386.5 \pm 19.8$ & $576.6 \pm 21.3$ \\
\hline
\end{tabular}

Differences between reduced and oxidized clays, all $\mathrm{P}<0.001$

Table 1: Capacitance ( $C$, farads) and resistance $(R$, ohms) in parallel at three different frequencies $(\mathrm{Hz})$ for reduced and oxidized clays.

\begin{tabular}{|c|c|c|c|}
\hline & $x$ & $y$ & $Y \%$ \\
\hline $120 \mathrm{~Hz} \mathrm{C}$ & $-0.916^{t+k+*}$ & $0.427^{\star}$ & $0.559^{* *}$ \\
\hline $120 \mathrm{~Hz} \mathrm{R}$ & $0.956^{*+* t}$ & $-0.427^{*}$ & $-0.677^{* *}$ \\
\hline $1 \mathrm{kHz} \mathrm{C}$ & $-0.947^{*+* *}$ & $0.42^{*}$ & $0.617^{* *}$ \\
\hline $1 \mathrm{kHz} \mathrm{R}$ & $0.963^{*+* t+}$ & $-0.428^{*}$ & $-0.681^{t+*+*}$ \\
\hline $10 \mathrm{kHz} \mathrm{C}$ & $-0.92^{* * *}$ & 0.352 & $0.594^{* *}$ \\
\hline $10 \mathrm{kHz} \mathrm{R}$ & $0.964^{+*+* t}$ & $-0.427^{*}$ & $-0.681^{t+* t+}$ \\
\hline
\end{tabular}

$\mathrm{P}<0.05^{*}, 0.01^{* *}, 0.001^{* * * *}$, and $0.0005^{* * * *}$ with $\mathrm{n}=20,1$-tailed t-test

Table 2: Correlations of capacitance $(C)$ and resistance $(R)$ in parallel with chromaticity coordinates at three different frequencies $(\mathrm{Hz})$.

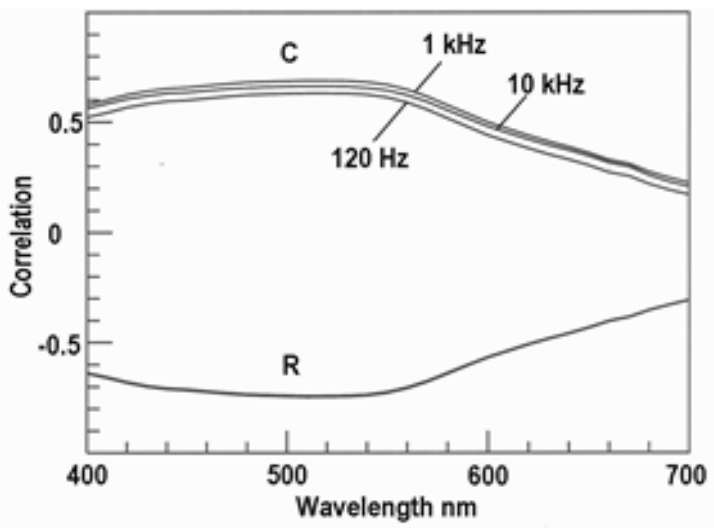

Figure 5: Correlations of fiber-optic reflectance with capacitance (C) and resistance $(\mathrm{R})$ at three frequencies $(\mathrm{Hz})$, all three frequencies for $\mathrm{R}$ gave the same result.

\section{Shale color}

Above the clay collection site was an erratic reef of Devonian fossil coral, Eridophyllum seriale [16]. The matrix between the corallites was only several millimeters in width and contained colored shale (Figure 6). As seen in Figure 7, the matrix permeating this ancient coral was within the statistical range of oxidized grayish-red shale.

\section{Groundwater stream hydrology}

The groundwater entering the stream above the colored clays tended to have a low $\mathrm{pH}$ in the winter and a high $\mathrm{pH}$ in the summer (Figure 8). The mean $\mathrm{pH}$ in the stream above the clay site was $7.24 \pm 0.23$ but increased $(\mathrm{P}<0.001, \mathrm{n}=70)$ as water passed over the clay site to $\mathrm{pH} 7.84$ \pm 0.21 as a consequence of $\mathrm{CO}_{2}$ degassing. Degassing was affected by water temperature through the year, so that water temperature was correlated with $\mathrm{pH}(\mathrm{r}=0.30, \mathrm{P}<0.01, \mathrm{n}=70)$.

\section{Discussion}

The suggestion that groundwater might be responsible for variations in clay color [7] deserves serious attention because colorful banded shales and clays are a conspicuous feature of many badlands and escarpments. Even the Munsell Rock Color book [11] displays

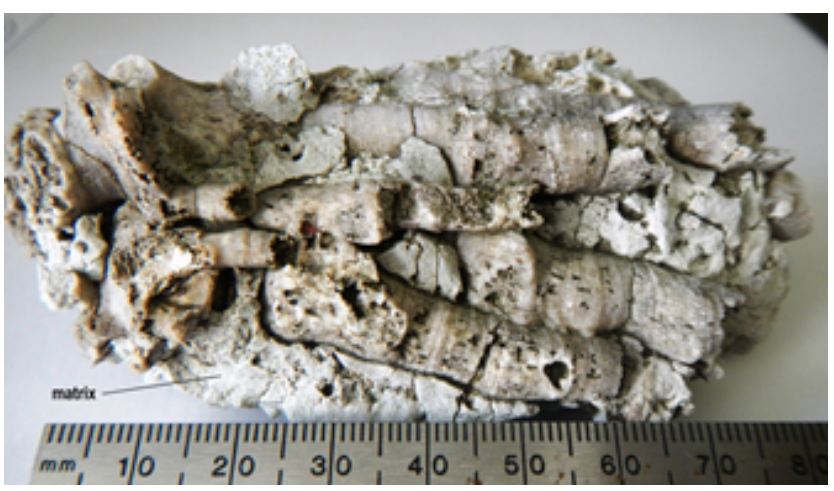

Figure 6: Shale matrix permeating the Devonian coral, Eridophyllum seriale.

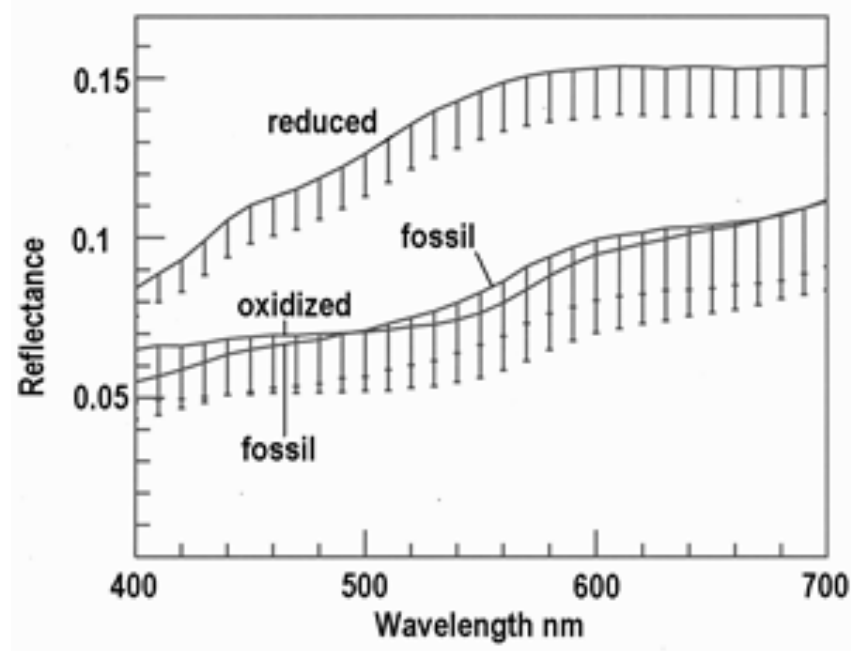

Figure 7: Fiber-optic reflectance spectra of reduced and oxidized Queenston Formation shales compared with the shale matrix between the corallites of the Devonian fossil coral, Eridophyllum seriale. Error bars show standard deviations. 
Citation: Swatland HJ (2017) Colored Clays in a Groundwater Stream, Correlating Fiber-optic Reflectance with Electrical Impedance. Hydrol Current Res 8: 283. doi: 10.4172/2157-7587.1000283

Page 4 of 4

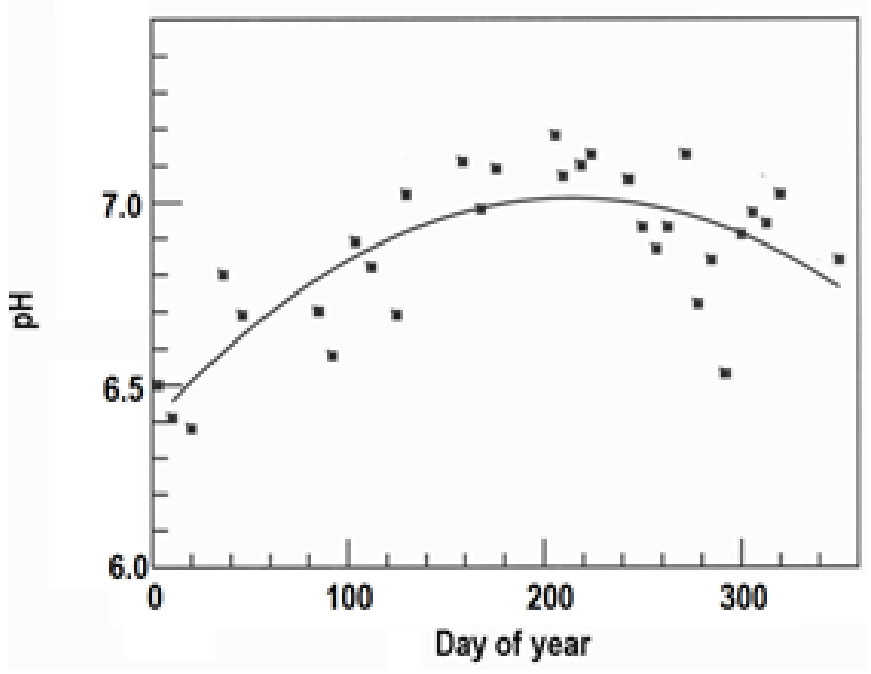

Figure 8: Seasonal variation in the $\mathrm{pH}$ of source groundwater passing over colored clays.

them as an attractive feature, and they appear in countless tourist images on the internet. The original suggestion by Vos [7] was continued by Rutka and Voss [17], and appears in Wikipedia [18] for all to see. But taking a critical approach, look at the acidity of groundwater (Figure 8) passing over alternating strata of greenish-gray and grayish-red clays (Figures 3 and 4). If acidity was the primary cause of color change, how could superficial color changes persist to create banded clays in a single stream? Also, the electrical impedance data (Table 1) showed that clay colors were not merely a surface effect caused by groundwater $\mathrm{pH}$ - there were deep difference in the clays. Thus, the superficial effects of groundwater acidity may be dismissed, which leaves the possibility that groundwater might have acted deep within strata over the long period of geological time. But this would require that various strata of shales and clays do not function as a blanket aquitard, and that they allow groundwater to penetrate through seams within clay strata. This is possible, but requires a proof.

Hence, at present, it seems more likely that color differences in the source shales and their derived clays were produced by depositional conditions during and after the Taconic Orogeny, when volcanic ash deposited along the eastern coast of North America was the dominant source of sediments [5]. Oxidized grayish-red shale in the matrix of a fossil coral (Figure 6) suggests that the grayish-red color originated in aerobic conditions, with the corollary, that greenish-gray shale originated in anaerobic conditions.

\section{References}

1. Potter PE, Maynard JB, Pryor WA (1980) Sedimentology of Shale: Study Guide and Reference Source. Springer-Verlag, Berlin, p: 313.

2. Chapman LJ, Putnam DF (1973) The Physiography of Southern Ontario. University of Toronto Press, Toronto, p: 386.

3. Tovell WM (1992) Guide to the Geology of the Niagara Escarpment. Niagara Escarpment Commission, Georgetown, Ontario, p: 159.

4. Brogly PJ, Martini IP, Middleton GV (1998) The Queenston formation shale-dominated mixed terrigenous-carbonate deposits of Upper Ordovician, semiarid, muddy shores in Ontario, Canada. Canadian Journal of Earth Sciences 35: 702-719.

5. Eyles N (2002) Ontario Rocks. Fitzhenry \& Whiteside, Markham, Ontario, p: 339.

6. Ferretti A, Cavalazzi B, Barbieri R, Westall F, Foucher F, et al. (2012) From black-and-white to color in the Silurian. Palaeogeography Palaeoclimatology Palaeoecology 367-368: 178-192.

7. Vos MA (1975) Potential Clay and Shale Resources of Central Ontario. Ontario Division of Mines, Toronto, p: 47.

8. Nagano T, Nakashima S, Nakayama S, Osada K, Senoo M (1992) Color variations associated with rapid formation of goethite from proto-ferrihydrite at $\mathrm{pH} 13$ and $40^{\circ} \mathrm{C}$. Clays and Clay Minerals 40: 600-607.

9. Scheinost AC, Chavernas A, Barrón V, Torrent J (1998) Use and limitations of second-derivative diffuse reflectance spectroscopy in the visible to near-infrared range to identify and quantify Fe oxide minerals in soils. Clays and Clay Minerals 46: 528-536.

10. Wilde P, Quinby-Hunt MS (2010) Paradoxes and perceptions in color identification of paleo-redox conditions in peletic rocks from diagenic to metamorphic grade: International. Journal of Geology 2: 29-35.

11. Munsell Rock Color Book (2009) Munsell Color. Grand Rapids, Michigan, USA, p: 16.

12. Billmeyer FW, Saltzman M (1981) Principles of Color Technology. New York: Wiley, New York, p: 240

13. Swatland HJ (1998) Computer Operation for Microscope Photometry. CRC Press, Boca Raton, Florida, USA, p: 238.

14. Mehran M, Arulanandan K (1977) Low frequency conductivity dispersion in clay-water-electrolye systems. Clays and Clay Minerals 25: 39-48.

15. Swatland HJ (2014) Reflectance versus transmittance: the effects of light scattering on red colorants (carmine, Amazonian red annatto, and Peruvian cochinilla rojo and rosada) in biological, textile and museum science. Color Research and Application 39: 599-606.

16. Shimer HW, Shrock RR (1944) Index Fossils of North America. Massachusetts Institute of Technology Press, Cambridge, Massachusetts, USA, p: 837.

17. Rutka MA, Vos MA (1993) The Clay Products Industry and Shale Resource in Southern Ontario. Ontario Geological Survey, USA, pp: 18-22.

18. Queenston Formation (2017) Available from: https://en.wikipedia.org/wiki/ Queenston_Formation (Accessed August 30, 2017). 